\section{PC-047 STUDY OF THE TRIGON DEPOT ALLERGY TEST (TRIAMCINOLONE AND EXCIPIENTS: CARBOXYMETHYLCELLULOSE, POLYSORBATE 80) DEVELOPED IN THE PHARMACY DEPARTMENT}

${ }^{1} \mathrm{P}$ Pacheco* , ${ }^{1} \mathrm{~N}$ Manresa-Ramón, ${ }^{1} \mathrm{MA}$ Meroño-Saura, ${ }^{1} \mathrm{MA}$ Carvajal-Sánchez, ${ }^{1} \mathrm{~S}$ Clavijos Bautista, ${ }^{1} \mathrm{TM}$ Rodríguez-Martínez, ${ }^{1} \mathrm{C}$ Fernández-Zamora, ${ }^{1} \mathrm{~J}$ Ibañez-Caturla, ${ }^{2} \mathrm{AM}$ MoraGonzález. 'Hospital General Universitario Morales Meseguer, Pharmacy, Murcia, Spain; ${ }^{2}$ Hospital General Universitario Morales Meseguer, Allergology, Murcia, Spain

\subsection{6/ejhpharm-2020-eahpconf.94}

Background and importance The development of skin tests is a booming diagnostic area in detecting the agent responsible for an allergic reaction.

Aim and objectives To describe the development and results of skin tests in the study of anaphylaxis by Trigon depot.

Material and methods A 52-year-old patient presented with generalised pruritus, local irritation and dyspnoea immediately after infiltration of Trigon depot. The allergology department asked the pharmacy department (PD) to prepare intraepidermal (prick test) and intradermal tests with the concentrated drug and serial dilutions of Trigon depot, triamcinolone, carboxymethylcellulose and polysorbate 80 . The PD carried out a bibliographic search to determine the physical form of the components, and their physical-chemical characteristics and conservation. There were no specific data on dilutions to these tests, so we relied on Al-Hadithy et al (2011).

The PD evaluated the effectiveness by the results of the skin tests. Possible false positives were taken into account.

Results We manufactured Trigon depot $40 \mathrm{mg} / \mathrm{mL}$ prick tests (from commercialised vial), carboxymethylcellulose $5 \mathrm{mg} / \mathrm{mL}$ (from commercialised eye drops), triamcinolone $1 \mathrm{mg} / \mathrm{mL}$ (from the substance powder using a $0.22 \mu \mathrm{m}$ filter) and polysorbate 80 (from docetaxel $20 \mathrm{mg} / \mathrm{mL}$ ). The intradermal syringes of Trigon and carboxymethylcellulose were prepared at serial dilutions of $1: 100$ and $1: 1000$, and triamcinolone and polysorbate 80 at dilutions of $1: 1,1: 10$ and $1: 100$.

According to good manufacturing practices, the process was carried out in a horizontal laminar flow hood, except for polysorbate 80 . Physical stability was evaluated by visual inspection to ensure homogeneity and it was packed in $1 \mathrm{~mL}$ syringes stored at $2-8^{\circ} \mathrm{C}$ for 48 hours protected from light. The results of the study were: negative skin tests for docetaxel (containing polysorbate 80 ) and triamcinolone; prick test with Trigon depot produced mild erythema; intradermal reaction with Trigon depot $(1: 100)$ was clearly positive with a $15 \times 10$ $\mathrm{mm}$ papule and erythema; and intradermal reaction with carboxymethyl cellulose $(1: 100)$ was positive with an $8 \mathrm{~mm}$ papule and erythema.

Conclusion and relevance In this multidisciplinary study, doctors and pharmacists have worked towards a common goal, the well being of the patient in the diagnosis of a rare anaphylactic reaction. It was concluded that the patient had undergone anaphylaxis due to carboxymethylcellulose contained in Trigon depot. This excipient is very common in the pharmaceutical industry. In fact, our patient had previously been exposed to Aquacel AG (contains carboxymethylcellulose) which acted as the primary sensitiser.

\section{REFERENCES AND/OR ACKNOWLEDGEMENTS}

No conflict of interest.

\section{PC-048 IMPORTANCE OF NON-STERILE FORMULATION IN A PAEDIATRIC HOSPITAL}

${ }^{1} \mathrm{D}$ Gavrus Ion, ${ }^{1} \mathrm{JM}$ Català Foguet, ${ }^{1} \mathrm{M}$ Sanchez Celma, ${ }^{1} \mathrm{JA}$ Cuartero Lozano, ${ }^{1} \mathrm{M}$ Villaronga Flaqué, ${ }^{1} \mathrm{R}$ Farre Riba, ${ }^{2} \mathrm{~F}$ Bossacoma Busquets*. ${ }^{1}$ Hospital Sant Joan De Déu, Pharmacy, Esplugues De Llobregat, Spain; ${ }^{2}$ Hospital Sant Joan De Déu/Fundació Salut Empordà, Pharmacy, Esplugues De Llobregat, Spain

\subsection{6/ejhpharm-2020-eahpconf.95}

Background and importance In a paediatric hospital, we often face the lack of commercially available medicines suitable or even licensed for use in paediatrics. Furthermore, authorised paediatric medicines, especially in younger children and neonates, may not always be age appropriate regarding dose, suitability of dosage forms and excipients. Compounding is the main solution to the problem, so the compounding area becomes essential in this type of centre.

Aim and objectives The objective was to detect the therapeutic groups (TG) which need the most compounded formulas in a paediatric hospital, to highlight the necessity of child friendly medicines.

Material and methods In 2018, a retrospective study was conducted analysing the different compounded formulas and amount of preparations, comparing data with the hospital formulary and classifying them according to specific therapeutic groups, in line with the anatomic, therapeutic, chemical classification system. Data were compared with the total hospital formulary references.

Results A total of 125 non-sterile compounded formulas with 105 different active ingredients were prepared, and were classified into compounded oral liquid forms (OLF), representing $46.5 \%$ of the total OLF of the hospital formulary, oral solid forms (OSF), representing $5.5 \%$ of the total OSF, and topical solid forms (TSO), representing $28 \%$ of the total TSO.

Conclusion and relevance The TG with the most need for compounded formulas were: cardiovascular disorders, digestive system and metabolism or nervous system. The hospital pharmacy of paediatric hospitals which care for complex patients

\begin{tabular}{|c|c|c|c|c|c|c|}
\hline TG & OLF & & OSF & & TSO & \\
\hline Formulas & Bottles & Formulas & Capsules & Formulas & Tubes & \\
\hline $\begin{array}{l}\text { Digestive and } \\
\text { metabolism }\end{array}$ & 18 & 2908 & 6 & 3350 & & \\
\hline $\begin{array}{l}\text { Blood and } \\
\text { haematopoietic } \\
\text { derivatives }\end{array}$ & 1 & 76 & 2 & 1800 & & \\
\hline Cardiovascular & 23 & 3667 & 4 & 4830 & 4 & 280 \\
\hline Dermatological & & & & & 2 & 45 \\
\hline Hormonal & 4 & 651 & 1 & 600 & & \\
\hline Anti-infective & 7 & 138 & 1 & 400 & & \\
\hline $\begin{array}{l}\text { Antineoplastic and } \\
\text { immunomodulatory }\end{array}$ & 8 & 529 & 1 & 770 & 3 & 217 \\
\hline Musculoskeletal & 4 & 108 & 10 & 22300 & & \\
\hline Nervous & 16 & 1622 & 5 & 2100 & 1 & 239 \\
\hline Antiparasitic & & & & & 1 & 6 \\
\hline Respiratory & 1 & 6 & & & & \\
\hline Organs of the senses & 1 & 78 & & & & \\
\hline Several & 1 & 3 & & & & \\
\hline
\end{tabular}


face many difficulties in providing age appropriate medicines regarding dose, suitability of the dosage form or excipient content. Compounding is the main solution.

\section{REFERENCES AND/OR ACKNOWLEDGEMENTS}

Acknowledgements to all pharmacy staff.

No conflict of interest.

\section{PC-049 IMIPENEM-CILASTATIN FORTIFIED EYE DROPS FOR THE TREATMENT OF CORNEAL ULCERS CAUSED BY CONTACT LENSES: DEVELOPMENT AND CHARACTERISATION}

P Pacheco*, N Manresa-Ramón, MÁ Carvajal-Sánchez, T Rodríguez-Martínez, MA MeroñoSaura, S Clavijos-Bautista, C Fernández-Zamora, J Ibañez-Caturla. Hospital General Universitario Morales Meseguer, Pharmacy, Murcia, Spain

\subsection{6/ejhpharm-2020-eahpconf.96}

Background and importance Corneal ulcers are a common problem that may appear more frequently in patients with inappropriate use of contact lenses. Unfortunately, it can be difficult to diagnose; its cause can be elusive and the consequences of an error in diagnosis or treatment can be severe.

Aim and objectives To describe the development of $0.5 \%$ imipenem-cilastatin eye drops and to evaluate the effectiveness and safety of this master formula.

Material and methods In February 2019, a 41-year-old woman presented to the emergency department for severe pain in the right eye. Commercial eye drops $(0.3 \%$ tobramycin and $0.5 \%$ moxifloxacin) were being applied. The ophthalmology department diagnosed an infiltrated corneal ulcer with an epithelial defect. Microbiological culture of the contact lenses was requested and Enterococcus faecalis and Achromobacter xylosoxidans were isolated. The antibiogram revealed sensitivity to $\beta$-lactams and resistance to tobramycin and quinolones. The ophthalmologist contacted the pharmacy service to select the most appropriate treatment, deciding on the development of 5\% ceftazidime and $0.5 \%$ imipenem fortified eye drops (1 drop every 2 hours). A corneal scraping was also carried out where growth of Fusarium spp was found. Therefore, therapy was completed with 1\% voriconazole (1 drop every 2 hours) and 5\% natamycin (1 drop every 4 hours).

A bibliographic search was made in PubMed and in the Spanish Society of Hospital Pharmacy, focusing on organoleptic characteristics, stability and $\mathrm{pH}$. Effectiveness and safety were evaluated in the medical history (Selene).

Results We manufactured $5 \mathrm{mg} / \mathrm{mL}$ imipenem-cilastatin eye drops from the vial for intravenous use and water for injection, working in a horizontal laminar flow cabinet and following the standardised work procedure. A $0.22 \mu \mathrm{m}$ filter was used. We established stability at $2-8^{\circ} \mathrm{C}$ for 2 days, protected from light. It was verified that a completely transparent liquid with $\mathrm{pH} 7$ had been obtained.

Conclusion and relevance Imipenem-cilastatin $0.5 \%$ eye drops proved to be a novel alternative in the treatment of corneal ulcers caused by Enterococcus faecalis and Achromobacter xylosoxidans. It produced a rapid and intense antibiotic effect that resulted in a reduction in eye inflammation. It was also easy to apply, which facilitated therapeutic compliance and contributed to a shorter hospital stay. Its safety and tolerance profiles were adequate.
REFERENCES AND/OR ACKNOWLEDGEMENTS

No conflict of interest.

\section{PC-050 IMPORTANCE OF COMPOUNDING IN THE PAEDIATRIC HOSPITAL PHARMACY}

${ }^{1} \mathrm{JM}$ Català Foguet, ${ }^{1} \mathrm{D}$ Gavrus Ion, ${ }^{1} \mathrm{M}$ Sánchez Celma, ${ }^{1} \mathrm{M}$ Villaronga Flaqué, ${ }^{1} \mathrm{R}$ Farré Riba, ${ }^{2}$ F Bossacoma Busquets*. ${ }^{1}$ Hospital Sant Joan De Déu, Pharmacy, Esplugues De Llobregat, Spain; ${ }^{2}$ Hospital Sant Joan De Déu/Fundació Salut Empordà, Pharmacy, Esplugues De Llobregat, Spain

\subsection{6/ejhpharm-2020-eahpconf.97}

Background and importance Paediatric pharmacy often faces a lack of commercially available medicines suitable or even licensed for use in children. Children cannot be regarded as small adults or as a homogeneous group in themselves. As a consequence, paediatric medicines should be appropriately designed for the target age group. Compounding is the main solution to this problem, so the compounding area becomes essential in this type of centre. Given the high number of requests for these formulations, including the most commonly used compounded preparations in the pharmacy formulary as standard preparations (SP) is a possible solution.

Aim and objectives To highlight the importance of compounding for obtaining child friendly dosage forms and formulations in a referral paediatric hospital.

Material and methods All SP included in the pharmacy formulary were identified and research was conducted to ensure that a suitable or licensed commercial product for paediatric patients was unavailable nationally and internationally. Using our compounding software, we quantified all SP made in 2017 due to the lack of a commercially available product and classified these according to their route of administration.

Results Our formulary included 99 SP compounded in our pharmacy department (table 1). Oral liquid compounded formulations (52) represented $35 \%$ of the total oral liquid drugs available in our formulary (148).

\begin{tabular}{lll} 
Abstract 3 PC-050 Table 1 & \\
\hline Compounding form & $\begin{array}{l}\text { Different active substances } \\
\text { formulated }\end{array}$ & $\begin{array}{l}\text { Prepared units per } \\
\text { year }\end{array}$ \\
\hline Oral liquid & 52 & 8300 \\
Solid & 16 & 25000 \\
Parenteral & 12 & 1879 \\
administration & & \\
Ocular topical & 5 & 524 \\
Topical & 13 & 1535 \\
Rectal & 1 & 22 \\
\hline
\end{tabular}

Table 2 describes the reasons for compounding our 99 SP.

Abstract 3PC-050 Table 2

\begin{tabular}{llll}
\hline $\begin{array}{l}\text { Commercially available with no } \\
\text { child friendly formulation } \\
\text { (dosage forms, administration } \\
\text { volume, dosage form size) }\end{array}$ & $\begin{array}{l}\text { Inappropriate } \\
\text { excipient for } \\
\text { children }\end{array}$ & $\begin{array}{l}\text { Available for a } \\
\text { different } \\
\text { treatment } \\
\text { indication }\end{array}$ & $\begin{array}{l}\text { For stability/ } \\
\text { sterility } \\
\text { requirements }\end{array}$ \\
\hline 81 & 2 & 3 & 13 \\
\hline
\end{tabular}

